\title{
Designing conservation strategies to preserve the genetic diversity of Astragalus edulis Bunge, an endangered species from western Mediterranean region
}

Julio Peñas, Sara Barrios, Javier Bobo-Pinilla, Juan Lorite, M. Montserrat Martínez-Ortega

Astragalus edulis (Fabaceae) is an endangered annual species from western Mediterranean region that colonized SE Iberian Peninsula, NE and SW Morocco, and the easternmost Macaronesian islands (Lanzarote and Fuerteventura). Although in Spain some conservation measures have been adopted, it is still necessary to develop an appropriate management plan to preserve genetic diversity across the entire distribution area of the species. Our main objective was to use population genetics as well as ecological and phylogeographic data to select Relevant Genetic Units for Conservation (RGUCs) as the first step in designing conservation plans for $A$. edulis. We identified six RGUCs for in situ conservation, based on estimations of population genetic structure and probabilities of the loss of rare alleles. Additionally, further population parameters, i.e. occupation area, population size, vulnerability, legal status of the population areas, and the historical haplotype distribution, were considered in order to establish which populations deserve conservation priority. Three populations from the Iberian Peninsula, two from Morocco, and one from the Canary Islands represent the total genetic diversity of the species and the rarest allelic variation. Ex situ conservation is recommended to complement the preservation of $A$. edulis, given that effective in situ population protection is not feasible in all cases. The consideration of complementary phylogeographic and ecological data is useful for management efforts to preserve the evolutionary potential of the species. 
1 Designing conservation strategies to preserve the genetic diversity of Astragalus

2 edulis Bunge, an endangered species from western Mediterranean region

3

4 Julio Peñas ${ }^{1}$, Sara B. Barrios ${ }^{2}$, Javier Bobo-Pinilla ${ }^{2}$, Juan Lorite ${ }^{1} \&$ M. Montserrat Martínez-Ortega ${ }^{2}$

$5{ }^{1}$ Plant Conservation Unit, Department of Botany, University of Granada. Granada, Spain.

$6{ }^{2}$ Department of Botany, University of Salamanca. Campus Miguel de Unamuno, Salamanca, Spain.

7

8 Corresponding Author:

9 Julio Peñas ${ }^{1}$

10 C/ Severo Ochoa s/n. Facultad de Ciencias. Unidad de Conservación Vegetal, Departamento de Botánica,

11 Universidad de Granada. E-18071 Granada, Spain.

12 Email address: jgiles@ugr.es 


\section{Abstract}

15 Astragalus edulis (Fabaceae) is an endangered annual species from western Mediterranean region that 16 colonized SE Iberian Peninsula, NE and SW Morocco, and the easternmost Macaronesian islands 17 (Lanzarote and Fuerteventura). Although in Spain some conservation measures have been adopted, it is still necessary to develop an appropriate management plan to preserve genetic diversity across the entire distribution area of the species. Our main objective was to use population genetics as well as ecological and phylogeographic data to select Relevant Genetic Units for Conservation (RGUCS) as the first step in designing conservation plans for $A$. edulis. We identified six RGUCs for in situ conservation, based on estimations of population genetic structure and probabilities of the loss of rare alleles. Additionally, further population parameters, i.e. occupation area, population size, vulnerability, legal status of the population areas, and the historical haplotype distribution, were considered in order to establish which populations deserve conservation priority. Three populations from the Iberian the species and the rarest allelic variation. Ex situ conservation is recommended to complement the preservation of $A$. edulis, given that effective in situ population protection is not feasible in all cases. The consideration of complementary phylogeographic and ecological data is useful for management efforts to preserve the evolutionary potential of the species.

\section{Keywords}

33 Threatened species, AFLPs, cpDNA sequencing, Relevant Genetic Units for Conservation, conservation priorities, phylogeography. 


\section{Introduction}

Although one of the central concepts in biodiversity conservation is that genetic diversity is crucial to ensure the survival of species, until now the conservation of plant genetic resources has received less attention than it deserves. Plant-conservation strategies have been commonly based on general premises, leading to more or less standardized systems for evaluating the extinction risks of the species (Moraes et al., 2014). However, plant species differ enormously in biological traits and environmental requirements, making it unrealistic to apply a single system to all species. Recent years have seen increasing efforts to improve both in situ and ex situ conservation methods, which in theory would foster dynamic conservation of plant species and populations (Volis \& Blecher, 2010; Heywood, 2014). Plant genetic diversity is spatially structured at different scales (e.g. geographical areas, populations, or among neighbouring individuals) (Engelhardt et al., 2014) as a result of environmental influences, lifehistory traits, and the demographic past history of the species. Therefore, management schemes for conservation often require an understanding of population dynamics and knowledge of relative levels of genetic diversity, within species genetic structure, as well as within- and among- population genetic differentiation in order to focus efforts on specific populations needing recovery (Haig, 1998; PérezCollazos et al., 2008).

\section{3}

Several estimators have been assayed to answer the question of which and how many populations deserve conservation priority, such as: Evolutionary Significant Units (ESUs; Ryder, 1986); Management Units (MUs; Moritz, 1994); Operational Conservation Units (OCUs; Doadrio et al., 1996); Fundamental Geographic and Evolutionary Units (FGEUs; Riddler \& Hafner, 1999); Functional Conservation Units (FCUs; Maes et al., 2004), among others (see also Pérez-Collazos et al., 2008, Domínguez-Domínguez \& Vázquez-Domínguez, 2009). Fraser \& Bernatchez (2001) reviewed the different concepts of ESUs (the 
60

61

62

63

64

65

66

67

68

69

70

71

72

most prominent estimator among those previously mentioned), concluding that differing criteria would work more dynamically than others and can be used alone or in combination depending on the situation. Pérez-Collazos et al. (2008), partially based on Caujapé-Castells \& Pedrola-Monfort (2004), as well as on the premises established by Ciofi et al. (1999), introduced the concept of Relevant Genetic Units for Conservation (RGUCs), which was subsequently used to propose sampling strategies for species such as Boleum asperum Desv. (Pérez Collazos et al., 2008) and Borderea pyrenaica Miégev. (SegarraMoragues \& Catalán, 2010). This approach combines two methods that use genetic data (considering both usual and rare alleles) to estimate the minimum number of conservation units (often corresponding to populations) that should be targeted for an adequate representation of the total (or partial) genetic variability of a threatened species, as well as a way to select among all units (i.e. populations) which contain a singular or rare allelic composition. A list of preferred sampling areas (PSA) indicating the geographical ranges with higher probabilities of capturing a particular rare allele is finally established, helping to identify RGUCs and therefore prioritize particular populations, as well as sampling for ex situ conservation. This method helps identify the most singular populations, based on the idea that rare alleles are essential in conservation because they represent unique evolutionary products that could provide the species with advantageous properties to cope with eventual environmental shifts. Thus, collection designs oriented to sampling rare alleles reinforce declining populations and may aid the survival of reintroduced plants (Bengtsson et al., 1995; Pérez Collazos et al., 2008). One of the main advantages of this genetic conservation approach is that it objectively prioritizes particular plant populations in low-extinction-risk categories (Segarra-Moragues \& Catalán, 2010), particularly in taxa that have many populations and individuals, making active protection and monitoring of the entire distribution area of the species difficult or unaffordable. 
83 The species selected for this study Astragalus edulis Bunge (Fabaceae), is an annual plant that inhabits

84 semidesertic areas of south-eastern Spain, western North Africa, and the Canary Islands (Fuerteventura

85 and Lanzarote) (Peñas, 2004; Reyes-Betancort et al., 2005). It is a threatened species evaluated as

86 Endangered (EN) in Spain. Despite its relatively wide distribution area, only a few populations remain,

87 these being highly fragmented. Habitat alteration has been cited as a major threat to this species

88 (Peñas, 2004). Specifically, the abandonment of traditional agricultural practices, overgrazing, and the

habitat depletion, caused by the spread of greenhouses, may have had severely negative consequences

for species survival (Benito et al., 2009). This species represents an ideal model to test the utility of

RGUC identification as an affordable way to conserve taxa that have highly fragmented populations, some of them with many individuals, but they are under extinction-risk categories.

93

Our specific aims are: (1) to evaluate the distribution of the genetic diversity among the different populations, and/or geographical areas; (2) to assess the number of populations that should be sampled or preserved in order to establish a representative percentage of the total genetic variation of $A$. edulis; (3) to identify which populations should be prioritized to better represent the genetic singularity and geographic variability for both ex situ and in situ conservation.

\section{Materials \& Methods}

Studied species information has been available on population sizes, except for the rough estimates by Peñas (2004), indicating that ca. 226,000 individuals were present in SE Spain in 2003. This estimate also indicated a 
107 noticeable inter-annual fluctuation in population sizes (number of individuals) and reproductive success

108 (Peñas, 2004; Reyes-Betancort et al., 2005). The reproductive biology of the species is poorly known; it 109 shows an entomophilous pollination syndrome, lacking asexual reproduction as well as evident 110 adaptations to long-distance dispersal, but there is no information available on its pollination biology or 111 dispersal agents. Its habitat is restricted to grasslands on poor sandy soils, resulting from erosion or 112 deposition of volcanic or schistose rocks in semiarid areas of the western Mediterranean region (Peñas, 113 2004; Reyes-Betancort et al., 2005) (Fig. 1).

115 Astragalus edulis is rare (i.e. constantly sparse in a specific habitat but over a large range; according 116 Rabinobitz, 1981) and threatened species evaluated as Endangered (EN) in Spain, and consequently 117 included in the Spanish national and regional red lists (Bañares et al., 2004), as well as in the Andalusian 118 (southern Spain) red list (Cabezudo et al., 2005). Also, some populations in Spain are included in Natura 1192000 network (Special Areas of Conservation, Council Directive 92/43/EEC) and in Regional Network of 120 Natural Protected areas of Andalusia (southern Spain), while the areas occupied by the species in Canary 121 Islands and Morocco lack legal protection.

Plant material for DNA study

We collected fresh leaf tissue from 360 individuals belonging to 17 populations; 6 from the Iberian Peninsula (AE1 to AE6), 8 from Morocco (AE7 to AE14) and 3 from the Canary Islands (AE15 to AE17), spanning the entire distribution range of the species (Table 1; Fig. 1). We considered different populations when individual are more than $1 \mathrm{~km}$ apart. We aimed to collect 25 individuals per population whenever possible but due to small population sizes in some cases the final number of individuals sampled per population ranged from 7 to 33 . Within a particular population the samples 
131 were collected at distances greater than $5 \mathrm{~m}$ apart to avoid sampling closely related individuals. All

132 sampling sites were geo-referenced with a GPS (GARMIN GPSMAP 60) and vouchers of the sampled

133 localities were included in the herbaria of the Universities of Salamanca (SALA) and Granada (GDA).

134 Plant material from each individual was dried and preserved in silica gel until DNA extraction.

DNA isolation, AFLP protocol and cpDNA sequencing

137

138 Total DNA was isolated following the 2x CTAB protocol (Doyle \& Doyle, 1987) with minor modifications.

AFLP profiles were drawn following established protocols (Vos et al., 1995) with modifications. A negative control sample was consistently included to test for contamination, and five samples taken at random were replicated to test for reproducibility. Selective primers were initially screened using 24 primer combinations for the selective PCR and three were finally selected (fluorescent dye in brackets):

generated a relatively high number (a high number of alleles per individual is desirable in conservation genetic studies given that AFLP are dominant markers; Lowe et al., 2004) of clearly reproducible bands,

for which homology was easy to ensure. The fluorescence-labelled selective amplification products were separated in a capillary electrophoresis sequencer (ABI 3730 DNA Analyzer; Applied Biosystems), with GenScan ROX (Applied Biosystems) as the internal size standard, at the Genomic Department of Universidad Politécnica de Madrid. Raw data with amplified fragments were scored and exported as a presence/absence matrix.

To complement the information of the mainly nuclear AFLPs, the plastid regions trnG-trnS, trnC-rpoB, 153 and tabF-tabC (Taberlet et al., 1991; Shaw et al., 2005) were explored. These regions showed the highest variability of 23 surveyed cpDNA regions in the preliminary studies using 10 individuals and were 
155 therefore used to analyse a total of 61 individuals (i.e., 3-4 individuals per population, due to 156 amplification failure in 7 cases) of $A$. edulis : 38 from Iberian Peninsula (IP), 17 from Morocco (M) and, 6 157 from Canary Islands (CI). PCR products were purified using PCR Clean-Up with ExoSAP-IT Kit 158 (AFFIMETRIX, Santa Clara, CA, USA) following the manufacturer's instructions. The cleaned amplification 159 products were analysed with a 3730 DNA Genetic Analyzer capillary sequencer (Applied Biosystems). All 160 sequences were deposited in GeneBank (pending).

Molecular Data analysis

An unrooted phylogram based on Nei and Li's genetic distances (Nei \& Li, 1979) and AFLP data were calculated using the Neighbour-Joining (NJ) clustering method, with 1000 bootstrap pseudoreplicates (BS), in order to evaluate genetic structure within A. edulis. This was conducted with the software PAUP v4.0b10 (Swofford, 1998). As an additional estimate of the population genetic structure and based on Dice's similarity coefficient (Dice, 1945; Lowe et al., 2004), a Principal Coordinate Analysis (PCoA) was performed with NTSYS-pc 2.02 (Rohlf, 2009) as an additional approach to the overall genetic relationships among the individuals analysed.

172 An analysis of molecular variance (AMOVA) was performed with the software ARLEQUIN 3.5.1.2

173 (Excoffier et al., 2005). The analysis was first conducted considering all populations belonging to the same group and, second, partitioning genetic variation into portions assignable to differences among three predefined groups (the three main geographic groups derived from the NJ phylogram, i.e. [IP: AE1AE6], [M: AE7-AE14], and [Cl: AE15-AE17]) in order to test for identifiable genetic structures among

177 geographical divisions. Significance levels of the variance components were estimated for each case 178 using non-parametric permutations with 1023 replicates. 
180 The proportion on polymorphic alleles measured by Nei's gene-diversity index (Nei, 1987) was 181 calculated for each population using the R package AFLPDAT for $\mathrm{R}$ (Ehrich, 2006). This package was also used to calculate the frequency down-weighted marker values per population or sampling site (DW; Schönswetter \& Tribsch, 2005), which estimates genetic rarity of a population as equivalent to range down-weighted species values in historical biogeographical research (Crisp et al., 2001). Finally, the number of rare alleles $\left(N_{r}\right)$, (i.e. bands that showed an overall frequency lower than $10 \%$, and that are present in less than $20 \%$ of the populations (Pérez-Collazos et al., 2008), was calculated as an additional measure of rarity.

The completeness of haplotype sampling across the range of $A$. edulis was estimated using the Stirling probability distribution. It provides a way to evaluate the assumption that all haplotypes have been sampled (Dixon, 2006). Plastid-DNA sequences were assembled and edited using GENEIOUS PRO ${ }^{\text {TM }} 5.4$ (Drummond et al., 2012) and aligned with CLUSTAL W2 2.0.11 (Larkin et al., 2007), and further adjustments were made by visual inspection. The resulting sequences were concatenated; the gaps longer than one base pair were coded as single-step mutations and treated as a fifth character state. An unrooted haplotype network was constructed using the statistical parsimony algorithm (Templeton et al., 1992) as implemented in TCS 1.21 (Clement et al., 2000), and used to infer the existing genealogical relationships.

Selection of Relevant Genetic Units for Conservation (RGUCS)

The selection of RGUCs is based on AFLP data and relies on the combination of two methods based on 
203 probability of rare-allele loss are compared with those of the degree of inter-population subdivision

204 (Caujapé-Castells \& Pedrola-Monfort, 2004; Pérez-Collazos et al., 2008).

205

206

First, the population-differentiation coefficient $\left(\mathrm{F}_{\mathrm{ST}}\right)$ obtained with ARLEQUIN was used to estimate the

207

208

209

210

211

212

213

214

215

216

217

218

219

220

221

222

223

224

225

226

total number of populations that should be targeted, according to the Ceska et al., (1997) equation modified $\mathrm{P}=1-\mathrm{F}_{\mathrm{ST}^{\mathrm{n}}}$ (Segarra-Moragues \& Catalán, 2010; but not Pérez-Collazos et al., 2008) where $n$ is the number of populations to be sampled to represent a given proportion $(P)$ of the among-population genetic diversity. For $A$. edulis, a $P$ value of $99.9 \%$ of the total genetic diversity was established, to cope properly with high conservation standards.

\section{Second, using the mean frequencies of rare bands (i.e. with an overall frequency lower than $10 \%$ and} present in less than $20 \%$ of the populations) and their associated probabilities of loss, the probability that a sample size on $N$ populations fails to include an allele with population frequency $p$ was calculated (Cajaupé-Castells \& Pedrola-Monfort, 2004; Pérez-Collazos et al., 2008). For this, the expression $L=(1$ p) $2 N$ (Bengtsson et al., 1995) was used, where $p$ represents the allele frequency and $N$ the number of populations in which a rare allele is present (Pérez-Collazos et al., 2008). For each rare allele, the observed (Lo) and expected (Le) probabilities of loss were calculated. The negative natural logarithms (-Log Lo and -Log Le) of those values were plotted (y-axis) against the mean frequency of each rare allele (x-axis) and used to calculate the respective linear regressions. The representative $R$ value (which indicates the proportion of rare alleles captured by sampling only one population) was calculated as the quotient between the slope of the expected regression line and the slope of the observed regression line, i.e. $R=m\left(-\log L_{e}\right) / m\left(-\log L_{o}\right)$ (Bengtsson et al., 1995; Caujapé-Castells \& Pedrola-Monfort, 2004; Pérez-Collazos et al., 2008; Segarra-Moragues \& Catalán, 2010). 
227 Several qualitative features of the populations and habitat disturbances were recorded during the field

228 work in order to combine them with the measures of genetic diversity. For this, we selected population

229 variables that were accounted as follows (adapted from IUCN, 2001): i) Occupation area: small $<1 \mathrm{~km}^{2}$

230 vs. large $>1 \mathrm{~km}^{2}$, ii) population size: high $>1,000$ individuals vs. low $<1,000$ individuals), iii) vulnerability:

231 stable $=$ with no disturbances or with minor disturbances $/$ declining $=$ with clear disturbance of both

232 individuals and habitat / critically declining = major disturbances, with major disturbance of individuals

233 and habitat; and iv) conservation status of the area: protected vs. unprotected.

234

235 Generalized linear models were used to test whether the main genetic diversity and rarity parameters

236 (i.e. $h_{\text {Nei, }}$ DW, and $\mathrm{Nr}$ ) show associations with qualitative population and conservation features.

237 Beforehand, to enhance the robustness of the models, we resampled the cases 10,000 times by

238 bootstrapping using the R boot package (Canty \& Ripley, 2013). Nei's diversity index and the frequency

239 of down-weighted marker values were fitted to Gaussian distributions, whereas the number of rare

240 alleles was fitted to a Poisson distribution. To test significant level differences of a given variable, we

241 used the glht function of the R multcomp package, indicated for multiple comparisons in generalized

242 linear models (Hothorn et al., 2008).

244 Results

245

246

Genetic variability and structure

247

248 A total of 1134 reliable polymorphic bands (averaging ca. 45 per individual per primer combination)

249 were found from the three primer pairs selected for the 360 individuals studied. The final error rate was 250 insignificant (1.67\%). The number of rare alleles, DW values and Nei's genetic diversity values 
251 corresponding to each population are given in Table 3. AFLPs detected low levels of intrapopulation

252 genetic diversity for $A$. edulis. Nei's gene diversity index ranged from a minimum value of 0.066 (AE7; in

253 the easternmost population of Morocco) to a maximum of 0.155 (AE5; in the central part of the Iberian

254 distribution of the species) and the diversity values were similar across all other populations studied.

255 The total species diversity was 0.108 . Regarding rarity, the genetically most distinctive population (DW =

256 5.713) appeared to be AE16 in Fuerteventura, while the lowest DW values were found in the

257 easternmost part of the Iberian core (AE6; DW = 1.507).

258

259

Both the unrooted NJ tree and the PCoA based on the entire data set (Fig. 2) revealed well-defined

genetic structure of populations in correspondence to geographic groups. The first group (Fig. 2a)

261

includes all populations from the Iberian Peninsula ( $85 \%$ BS), a second cluster those from Morocco $(74 \%$

BS) and the third those from the Canary Islands (100\% BS), plus some individuals from Morocco (two

samples from AE9), although the relationship between these latter two groups is weak (62\% BS) and the

Moroccan part of this cluster seems to be closely related to the remaining Moroccan individuals. The

same geographical groups are revealed by the PCoA (Fig. 2b), but in this case the apparently close

relationship between some of the Moroccan and all the Canarian samples suggested by NJ does not

seem to be supported, while an affinity between the Moroccan and the Iberian individuals is suggested.

The first three axes account for $13.2,6.4$, and $4.7 \%$ of the total variance, respectively.

AMOVA analysis of the entire data set as a single group (Table 4) revealed that the genetic variation among individuals $(71.06 \%)$ is meaningfully higher than the variation among populations $\left(28.94 \%, \mathrm{~F}_{\mathrm{ST}}=\right.$ 
274 differences among these geographical areas $\left(F_{S T}=0.346, p<0.001\right)$, while only $10.14 \%$ of the variance is

275 attributed to differences among populations within these three geographic groups.

276

277 The length of the three cpDNA regions for 61 individuals was 712 to $926 \mathrm{bp}$, and resulted in an 278 alignment of 2545 bp (2549 characters with indels coded). The genetic variability within A. edulis was 279 remarkably low (26 cpDNA regions initially tested, 3 of them used to analize a total of 61 individuals), 280 and all the mutations together defined a total of 7 haplotypes. The completeness of haplotype sampling 281 estimated using Dixon's (2006) method was 0.95 (most likely value of haplotypes $=7.002$ ), suggesting that all haplotypes present in the species were sampled. TCS implied a 95\% parsimony network with a maximum limit of five steps (Fig. 3). The most frequent haplotype (I) was found in five populations from the Iberian Peninsula and in the north-eastern Moroccan populations, while the second most frequent haplotype (IV) was represented in four western Moroccan populations and also in two Iberian populations. Within the Iberian Peninsula, two endemic haplotypes (III and V) were found and the western Moroccan populations also showed two endemic haplotypes (II and VI). A single endemic haplotype (VII) was found in Fuerteventura and Lanzarote (Fig. 3; Table 3).

Identification of RGUS

According to our results, $99.9 \%$ of the overall genetic diversity through the entire distribution range of $A$. edulis would be represented by just 6 populations $(\mathrm{N}=5.69)$. This should be the minimum number of populations to be targeted for suitable conservation. Of the total 1134 alleles detected by the AFLP analysis, 273 complied with the established rarity criteria (Table 3; Appendix 1). Of these rare alleles, 66 
298

300

301

302

303

304

305

306

307

308

309

310

311

312

313

314

315

316

317

318

319

320

321

available upon request). The representative R-value (i.e. proportion of rare alleles determined by sampling only one population) considering $A$. edulis as one group was $\mathrm{R}=0.354$. This means that the sampling of a single population of the entire distribution area of the species would represent the $35.4 \%$ of the whole set of rare alleles of the species. This value, calculated independently for each geographic area, showed slight variations (i.e. IP: $\mathrm{R}=0.407, \mathrm{M}: \mathrm{R}=0.355$ and $\mathrm{Cl}: \mathrm{R}=0.293$ ). Based on the mean frequencies of the rare alleles, as well as on their distribution among populations, the areas where each of these alleles had the highest probability of being found by randomly sampling one population were: IP (124), $\mathrm{M}(92)$, and $\mathrm{Cl}$ (57). Thus, the optimal proportion of populations to be sampled for conservation purposes from each geographical group can be expressed as 0.45 (IP): 0.34 (M): 0.21 (CI).

Approximately half of the A. edulis populations (9/17) occupy large areas $\left(>1 \mathrm{~km}^{2}\right)$, but only 7 populations exceed 1000 individuals (Table 3). Most of the Iberian populations show large occupation areas, population sizes, and stable or moderate habitat decline. By contrast, the Moroccan populations present smaller occupation areas, population sizes, and usually severe habitat decline. Only four populations from the Iberian Peninsula occupy protected areas, e.g. within Special Areas of Conservation of the Natura 2000 network or Andalusia regional system of protected areas (RENPA Network), while the areas occupied by the remaining populations lack legal protection.

The generalized linear model (Table 5) revealed significant influence for most of the geographic and population variables on the main genetic diversity and rarity parameters. Geographically, the Iberian Peninsula and Canary Islands accounted for higher genetic diversity than did Moroccan populations. Also, as expected, a significantly higher genetic diversity and rarity (Nei's diversity index, frequency down-weighted marker values, and number of rare alleles) was found in populations occupying larger areas, with higher numbers of individuals, stable populations, and locations in protected areas. 
Discussion

324

Genetic variability and structure

326

327

Although we are aware that AFLP-based estimates of the level of genetic variation are difficult to compare across studies (Nybom, 2004), the genetic-variation levels when standardizing sample size by population (i.e. indicating that relative differences in population diversity are not an artefact of the sampling effort) in A. edulis appear to approach those found in another annual species, Hypochaeris salzmanniana (Ortiz et al., 2007), which has a comparable distribution area (south-western Spain and Atlantic coast of Morocco). The diversity levels found are also comparable to those of other

to Astragalus (A. cremnophylax; Travis et al., 1996), or even long-lived western Mediterranean trees

(Juniperus thurifera, Terrab et al., 2008). Nevertheless, AFLPs have relatively low genetic diversity in $A$. edulis populations, compared to that of the Iberian narrow endemic steppe shrubs Boleum asperum

(Pérez-Collazos et al., 2008) and Vella pseudocytisus subsp. paui (Pérez-Collazos \& Catalán 2006).

Diversity as well as rarity values are particularly useful when used to compare populations or geographic areas occupied by the study species. In $A$. edulis the maximum diversity and rarity values within the Iberian distribution range correspond to the most central populations (AE4 and AE5), and within Morocco the AE8 and AE9 populations (Table 3; Fig. 1). Contrarily, on the easternmost edge of the 343 distribution area of the species some of the lowest diversity and rarity values were found, i.e. AE6 (IP) 344 and AE7 (M). The central parts of the Iberian distribution of this species may represent a long-term in 345 situ survival area. By contrast, the easternmost Iberian population AE6 could be the result of a single 
346

347

dispersal event, the extremely low genetic-diversity and rarity values indicating a genetic bottleneck. Within Morocco AE8 is a large population (several hundred individuals) and could have acted as a source area, as confirmed also by the NJ analysis (Fig. 2a). Meanwhile, AE7, with less than 20 individuals, could also have resulted from a single dispersal event. This hypothetical fine-scale west to east colonization pattern described for the Iberian Peninsula parallels that observed in Morocco and the low diversity and rarity values found in the easternmost Iberian and Moroccan sampling sites (AE6-AE7) may indicate that the eastward colonization history of the species in these areas might have been affected by founder effects and genetic bottleneck. This mode of peripheral founder events in small populations may be key in the future genetic differentiation of populations, as described for other plant species (e.g. Tremetsberger et al., 2003; Pérez-Collazos et al., 2008). In both the Iberian Peninsula and Morocco, aridity is higher eastwards, which on one hand may hamper future survival of these easternmost populations but, on the other, may promote new genetic variants as a response to environmental selection pressure.

In the Canary Islands, diversity and rarity reached their highest levels in AE16 (Fuerteventura), and their lowest levels in AE15 (Lanzarote). Considering that both islands emerged as a single proto-island and remained together as recently as the late Pleistocene (Fernández-Palacios et al., 2011), the current $A$. edulis distribution could be the product of an ancient long-distance dispersal event, a recent longdistance dispersal event, or the result of range fragmentation. The observed diversity and rarity values seem to favour the hypothesis of a rather recent long-distance dispersal event from Fuerteventura to Lanzarote. In any case, AE15, as well as AE7 and AE6, had been affected by founder effects and genetic bottlenecks probably related to genetic $\mathrm{drift}$. 
369 The overall AMOVA analysis led to the conclusion that most of the overall genetic variation of the

370 species could be attributed to intrapopulational (inter-individual) variability, while a smaller percentage

371 of the total variation appeared among populations (Table 4). Comparing our findings with those

372 resulting with AFLPs for other species from the western Mediterranean, either with similar distribution

373 areas (Ortiz et al., 2007; Terrab et al., 2008), or Iberian narrow endemic steppe plants (Pérez-Collazos \&

374 Catalán, 2006; Pérez-Collazos et al., 2008), we detected similar patterns and divergence levels. Also

375 similar patterns were found for the tree J. thurifera, which shows a wider distribution area, and

376 surprisingly they also parallel those shown by the perennial shrubs B. asperum and V. pseudocytisus ssp.

377 paui, which are very narrow endemics from NE Spain. It is well known that long-lived and outcrossing

378 species retain most of their genetic variability within populations and, by contrast, annual and/or selfing

379 taxa allocate most of the genetic variability among populations (Nybom, 2004). Nevertheless, we found

380 similar high levels of within-population diversity for the annual $A$. edulis than for the perennials $J$.

381 thurifera, B. asperum, and V. pseucocytisus ssp. paui, while for the annual herb $H$. salzmanniana the

382 levels of inter-individual (within population) genetic variability are significantly lower (Ortiz et al., 2007).

383 These data support the idea that the levels of intrapopulation genetic diversity are relatively high for an

384 annual species, perhaps facilitating the preservation of the gene pool of the species and, therefore, of

385 the evolutionary processes that generate and maintain it.

386

Designing conservation strategies: selection of RGUCS

388

Astragalus edulis has a relatively high number of populations and number of individuals (at least in the

large Spanish core), hampering the protection in situ of the entire distribution range of the species, and

thus populations need to be identified to apply conservation measures. To select the populations 
393 influenced the evolutionary history of the species lineages (Frankham et al., 2009). The selection of

394 RGUCs has enabled the estimation of the number of populations that should be targeted to sample

$39599.9 \%$ of the total genetic diversity of $A$. edulis. This approach helps to select particular populations that

396 should be prioritized because they have a singular allelic composition. The probabilities of rare-allele

397 loss indicate that the proportions that should be preserved from each geographical group should be

$3980.45(\mathrm{IP}): 0.34(\mathrm{M}): 0.21(\mathrm{Cl})$. Considering the diversity and rarity values found for each population based on

399 AFLP data and also this optimal proportion of populations to be sampled for conservation purposes from

400 each geographical group, we would initially recommend the priority selection of populations AE1, AE4

401 and AE5 (IP), AE8 and AE9 (M) and AE16 (Cl). Nevertheless, linking genetic diversity and rarity with

402 qualitative population and conservation features, we have found that Astragalus edulis exhibit a 403 significantly higher genetic diversity and rarity in populations occupying larger areas, with higher 404 numbers of individuals, stable populations, and locations in protected areas. That is the case of 405 populations AE4, AE5 but not of populations AE1, AE9 and AE16.

406

407 This selection of RGCUs based on AFLP data and population parameters could be complemented with 408 the available information on haplotypes. The presence of endemic haplotypes in the three main geographical groups suggests an impact of the biogeographic barriers in the study area (Atlantic Ocean, Atlas Mountains, Alboran Sea) in shaping A. edulis genetic diversity and divergence. Haplotypes endemic to restricted areas represent singular genetic variants that may have evolved separately from each other and, therefore, they deserve particular conservation efforts. Within the Iberian distribution range of the species, populations AE4 and AE5 show maximum diversity and rarity values and their sampling may

414 warrant conservation of the Iberian endemic haplotypes III and V, apart from the widely distributed 415 haplotypes I and IV (Table 3; Fig. 3). The selection of AE1, the Iberian population with the next highest 416 singularity value, would additionally contribute to the conservation of the endemic haplotype V. Within 
417 the Canary Islands, population AE16 registers comparatively the highest values of singularity and

418 diversity; moreover, the selection of AE16 for conservation purposes would warrant the conservation of 419 haplotype VII, which is endemic to these islands. Within Morocco, populations AE8 and AE9 have 420 comparatively the highest values of singularity and diversity, but haplotypes endemic to N Africa -II and

$421 \mathrm{VI}$, which are present in populations $\mathrm{AE} 11$ and $\mathrm{AE} 10$, respectively - would not be represented by the 422 selection of AE8 and AE9. The protection of populations AE11 and AE10 would also be highly desirable, 423 because in this case the evolutionary history based on the cpDNA of $A$. edulis in this geographic area 424 would also be taken into account. Given that the Moroccan populations of this species show medium 425 levels of genetic diversity and rarity (considering the overall values of $A$. edulis), our final decision on which particular populations from N Africa deserve priority for conservation would probably be more 427 accurate if based on the consideration of these rare or restricted haplotypes. From this perspective, 428 AE10 and AE11 could be prioritized over AE8 or AE9, although this decision should be taken with care given that our sampling may be low despite the results obtained from Dixon's test. The protection of large populations and smaller dispersed patches usually help preserve genetic integrity and diversity 431 (Alexander et al., 2004), but some selected RGUCs for $A$. edulis have small occupation areas and population sizes, and are critically vulnerable.

Several conservation measures could be implemented for the populations selected, e.g. studies to gather data on spatial distribution, population-size fluctuations, habitat quality, and fitness trends (Morris \& Doak, 2002), reinforcement of the smallest populations, and ex situ conservation in seed banks (Peñas, 2004). Indeed, in order to preserve Astragalus edulis at long-term, including the evolutionary potential of its populations, are needed ex situ collections (e.g. botanical gardens and seed banks; Guerrant et al., 2004) combined with any real in situ conservation value (Cavender et al., 2015). 
441 The identification of highly representative populations based on genetic data is essential to design

442 appropriate conservation guidelines, especially because this species is listed in a threat UICN category.

443 In biological conservation it is useful to combine molecular data with additional environmental,

444 ecological, and biological data sets in multidisciplinary approaches (Habel et al., 2015). The method

445 followed here to choose RGUCs draws not only on the approach of other authors (Ciofi et al., 1999;

446 Pérez-Collazos et al., 2008; Segarra-Moragues \& Catalán, 2010), but also on complementary

447 phylogeographic, population, and ecological data. Therefore, could be more comprehensive and also

448 perhaps more useful for management efforts that should prioritize populations to preserve the

449 evolutionary potential of the species (Rumeu et al., 2014).

450

\section{ACKNOWLEDGEMENTS}

452 We are grateful to L.M. Muñoz, J.A. Elena, S. Andrés, X. Giráldez, B. Benito, C. Oyonarte, and A. Abad for 453 their help during field work. We thank A. Abad also for helping with the lab work. We are grateful to D. 454 Nesbitt for the English-language revision.

455

456

\section{References}

458 Alexander JA, Liston A, Popovich SJ (2004) Genetic diversity of the narrow endemic Astragalus oniciformis (Fabaceae). American Journal of Botany 91(12):2004-2012

Bañares A, Blanca G, Güemes J, Moreno JC, Ortiz S (eds.) (2004) Atlas y Libro rojo de la Flora Vascular Amenazada de España. Dirección General de Conservación de la Naturaleza. Madrid

Benito BM, Martínez-Ortega MM, Muñoz LM, Lorite J, Peñas J (2009) Assessing extinction-risk of the spread of greenhouses. Biodiversity and Conservation 18(9):2509-2520 
465

466

467

468

469

470

471

472

473

474

475

476

477

478

479

480

481

482

483

484

485

486

487

Bengtsson BO, Weibull P, Ghatnekar L (1995) The loss of alleles by sampling: A study of the common outbreeding grass Festuca ovina over three geographic scale. Hereditas 122:221-238

Cavender N, Westwood M, Bechtoldt C, Donnelly G, Oldfield S, Gardner M, Rae D, McNamara W (2015) Strengthening the conservation value of ex situ tree collections. Oryx 49(3):416-424

Cabezudo B, Talavera S, Blanca G, Salazar C, Cueto M, Valdés B, Hernández-Bermejo JE, Herrera CM, Rodríguez C, Navas D (2005) Lista Roja de la flora vascular de Andalucía. Consejería de Medio Ambiente, Junta de Andalucía, Sevilla

Cajaupé-Castells J, Pedrola-Monfort J (2004) Designing ex situ conservation strategies through the assessment of neutral genetic markers: Application to the endangered Androcymbium gramineum. Conservation Genetics 5:131-144

Canty A, Ripley B (2013) boot: Bootstrap R (S-Plus) Functions. R package version 1.3-9

Ceska JF, Affolter JM, Hamrick JL (1997) Developing a sampling strategy for Baptisia arachnifera based on allozyme diversity. Conservation Biology 11:1133-1139

Ciofi C, Beaumont MA, Swingland IR, Bruford MW (1999) Genetic divergence and units for conservation in the Komodo dragon Varanus komodoensis. Proceedings of the Royal Society of London Series B, Biological Sciences 266:2269-2274

Clement M, Posada D, Crandall KA (2000) TCS: a computer program to estimate gene genealogies. Molecular Ecology 9:1657-1659

Crisp MD, Laffan S, Linder HP, Monro A (2001) Endemism in the Australian flora. Journal of Biogeography 28:183-198

Dice LR (1945) Measures of the amount of ecologic association between species. Ecology 26(3):297-302.

Dixon CJ (2006) A means of estimating the completeness of haplotype sampling using the Stirling probability distribution. Molecular Ecology Notes 6:650-652. 
488 Doadrio I, Perdices A, Machordom A (1996) Allozymic variation of the endangered killifish Aphanius 489 iberus and its application to conservation. Enviromental Biology of Fishes 45:259-271

490

491

492

493

494

495

496

497

498

499

500

501

502

503

504

505

506

507

508

509

510

511

Domínguez-Domínguez O, Vázquez-Domínguez E (2009) Filogeografía: aplicaciones en taxonomía y conservación. Animal Biodiversity and Conservation 32(1):59-70

Doyle JJ, Doyle JL (1987) A rapid DNA isolation procedure for small quantities of fresh leaf tissue. Phytochemical Bulletin 19:11-15

Drummond AJ, Ashton B, Buxton S, Cheung M, Cooper A, Duran C, Field M, Heled J, Kearse M, Markowitz S, Moir R, Stones-Havas S, Sturrock S, Thierer T, Wilson A (2012) Geneious v 5.5.7. Biomatters Ltd. Available from http://www.geneious.com. Accessed 20 July 2015

Ehrich D (2006) AFLPdat: a collection of R functions for convenient handling of AFLP data. Molecular Ecology Notes 6:603-604

Engelhardt KAM, Lloyd MW, Neel MC (2014) Effects of genetic diversity on conservation and restoration potential at individual, population, and regional scales. Biological Conservation 179:6-16

Excoffier L, Laval G, Schneider S (2005) Arlequin ver. 3.0: An Integrated software package for population genetics data analysis. Evolutionary Bioinformatics Online 1:47-50

Fernández-Palacios, J.M., de Nascimento, L., Rüdiger, O., Delgado, J. D., García-del-Rey, E., Arévalo, J.R. \& Whittaker, R.J. (2011) A reconstruction of Palaeo-Macaronesia, with particular reference to the long-term biogeography of the Atlantic island laurel forests. Journal of Biogeography, 38, 226-246

Fraser DJ, Bernatchez L (2001) Adaptive evolutionary conservation: towards a unified concept for defining conservation units. Molecular Ecology 10:2741-2752

Frankham R, Ballou JD, Briscoe DA (2009) Introduction to Conservation Genetics. Cambridge University Press

Guerrant Jr EO, Havens K, Maunder M (eds). (2004). Ex Situ Plant Conservation: Supporting Species Survival in the Wild. Island Press 
512 Habel JC, Zachos FE, Dapporto L, Rödder D, Radespiel U, Tellier A, Schmitt T (2015) Population genetics

513 revisited - towards a multidisciplinary research field. Biological Journal of the Linnean Society

$514 \quad 115(1): 1-12$

515 Haig SM (1998) Molecular contributions to conservation. Ecology 79(2):413-425

516 Heywood VH (2014) An overview of in situ conservation of plant species in the Mediterranean. Flora

$517 \quad$ Mediterranea 24:5-24

518 Hothorn T, Bretz F, Westfall P (2008) Simultaneous inference in general parametric models. Biometrical

519 Journal 50(3):346-363

520 IUCN (2001) 2001 IUCN Red List Categories and Criteria version 3.1.

521 http://www.iucnredlist.org/technical-documents/categories-and-criteria/2001-categories-criteria.

$522 \quad$ Accessed 2 March 2015

523 Larkin MA, Blackshields G, Brown NP, Chenna R, McGettigan PA, McWilliam H, Valentin F, Wallace IM,

524 Wilm A, López R, Thompson JD, Gibson TJ, Higgins DG (2007) Clustal W and Clustal X version 2.0.

$525 \quad$ Bioinformatics 23:2947-2948

526 Lowe A, Harris S, Ashton P (2004) Ecological Genetics: Design, Analysis and Application. Blackwell

$527 \quad$ Science Ltd

528 Maes D, Vanreusel W, Talloen W, Van Dyck H (2004) Functional conservation units for the endangered

529 Alcon Blue butterfly Maculinea alcon in Belgium (Lepidoptera: Lycaenidae). Biological Conservation

$530 \quad 120: 233-245$

531 Moraes, MA, Borgesa RAX, Martinsa EM, Fernandesa RA, Messinaa T, Martinelli G (2014) Categorizing

532 threatened species: an analysis of the Red List of the flora of Brazil. Oryx 48(2):258-265

533 Moritz C (1994) Defining "Evolutionarily Significant Units" for conservation. Tree 9:373-375

534 Morris WF, Doak DF (2002) Quantitative Conservation Biology. Theory and Practice and Population

535 Viability Analysis. Sinauer Associates Inc. Sunderland, Massachusetts 
536 Nei M (1987) Molecular evolutionary genetics. Columbia University Press, New York

537 Nei M, Li W (1979) Mathematical model for studying genetic variation in terms of restriction

$538 \quad$ endonucleases. PNAS 76:5269-5273

539 Nybom H (2004) Comparison of different nuclear DNA markers for estimating intraspecific genetic

540 diversity in plants. Molecular Ecology 13:1143-1155

541 Ortiz MA, Tremetsberger K, Talavera S, Stuessy T, García-Castaño JL (2007) Population structure of

542 Hypochaeris salzmanniana D.C. (Asteraceae), an endemic species to the Atlantic coast on both sides

543 of the Strait of Gibraltar in relation to Quaternary sea level changes. Molecular Ecology 16:541-552

544 Peñas J (2004) Astragalus edulis Bunge. In: Bañares A, Blanca G, Güemes J, Moreno JC, Ortiz S (eds) Atlas

545 y libro rojo de la flora vascular amenazada de España. Dirección General de Conservación de la

$546 \quad$ Naturaleza, Madrid, pp. 614-615

547 Pérez-Collazos E, Catalán P (2006) Palaeopolyploidy, spatial structure and conservation genetics of the

548 narrow steppe plant Vella pseudocytisus subsp. paui (Vellinae, Cruciferae). Annals of Botany

$549 \quad 97: 635-647$

550 Pérez-Collazos E, Segarra-Moragues JG, Catalán P (2008) Two approaches for the selection of Relevant

551 Genetic Units for Conservation in the narrow European endemic steppe plant Boleum asperum

552 (Brassicaceae). Biological Journal of the Linnean Society 94:341-354

553 Rabinowitz D (1981) Seven forms of rarity. pp. 205-217. In: The Biological aspects of rare plant

$554 \quad$ conservation. Ed. by H Synge. Wiley

555 Reyes-Betancort JA, León Arencibia MC, Wildpret de la Torre W, García Casanova G (2005) Adiciones a la

556 flora vascular de la isla de Lanzarote (Canarias). IV. Vieraea 33:527-538

557 Riddler BR, Hafner DJ (1999) Species as units of analysis in ecology and biogeography: time to take the

558 blinders off. Global Ecology Biogeography 8:433-441

559 Rohlf FJ (2009) NTSYSpc: Numerical Taxonomy System, ver. 2.21n. Exeter Software, Setauket, New York 
560 Rumeu B, Vargas P, Jaén-Molina R, Nogales M, Caujapé-Castells J (2014) Phylogeography and genetic

561 structure of the threatened Canarian Juniperus cedrus (Cupressaceae). Botanical Journal of the

$562 \quad$ Linnean Society 175(3):376-394

563 Ryder OA (1986) Species conservation and systematics: the dilemma of subspecies. TREE 1:9-10

564 Schönswetter P, Tribsch A (2005) Vicariance and dispersal in the alpine perennial Bupleurum stellatum L.

565 (Apiaceae). Taxon 54:725-732

566 Segarra-Moragues JG, Catalán P (2010) The fewer and the better: prioritization of populations for

567 conservation under limited resources a genetic study with Borderea pyrenaica (Dioscoreaceae) in

568 the Pyrenean National Park. Genetica 138:363-376

569 Shaw J, Lickey EB, Beck JT, Farmer SB, Liu W, Miller J, Siripun KC, Winder CT, Schilling EE, Small RL (2005)

570 The tortoise and the hare II: relative utility of 21 noncoding chloroplast DNA sequences for

571 phylogenetic analysis. American Journal of Botany 92:142-166

572 Surina B, Schönswetter P, Schneeweiss GM (2011) Quaternary range dynamics of ecologically divergent

573 species (Edraianthus serpyllifolius and E. tenuifolius, Campanulaceae) within the Balkan refugium.

$574 \quad$ Journal of Biogeography 38:1381-1393

575 Swofford DL (1998) PAUP* Phylogenetic Analysis Using Parsimony (*and Other Methods) (version

576 4.0b10). Sinauer Associates. Sunderland, Massachusetts

577 Taberlet P, Gielly L, Pautou G, Bouvet J (1991) Universal primers for amplification of three non-coding

578 regions of chloroplast DNA. Plant Molecular Biology 17:1105-1109

579 Templeton AR, Crandall KA, Sing CF (1992) A cladistic analysis of phenotypic associations with

580 haplotypes inferred from restriction endonuclease mapping and DNA sequence data. III. Cladogram

$581 \quad$ estimation. Genetics 132:619-633 
582 Terrab A, Schönswetter P, Talavera S, Vela E, Stuessy TF (2008) Range-wide phylogeography of Juniperus

583 thurifera L., a presumptive keystone species of western Mediterranean vegetation during cold

584 stages of the Pleistocene. Molecular Phylogenetics and Evolution 48:94-102

585 Travis SE, Manchinski J, Keim P (1996) An analysis of genetic variation in Astragalus cremnophylax var.

586 cremnophylax, a critically endangered plant, using AFLP markers. Molecular Ecology 5:735-745

587 Tremetsberger K, Stuessy TF, Samuel RM, Baeza CM, Fay MF (2003) Genetics of colonization in

588 Hypochaeris tenuifolia (Asteraceae, Lactuceae) on Volcan Lonquimay, Chile. Molecular Ecology

$589 \quad 12: 2649-2659$

590 Volis S, Blecher M (2010) Quasi in situ: a bridge between ex situ and in situ conservation of plants.

$591 \quad$ Biodiversity and Conservation 19: 2441-2454

592 Vos P, Hogers R, Bleeker M, Reijans M, Van de Lee T, Hornes M, Frijters A, Pot J, Peleman J, Kuiper M, 593 Zabeau M (1995) AFLP: a new technique for DNA fingerprinting. Nucleic Acids Reserch 23(21):4407594 4414

595 
596 Table 1. Geographic features of the populations sampled in the study. (N) Number of individuals used for

597 the AFLP analyses.

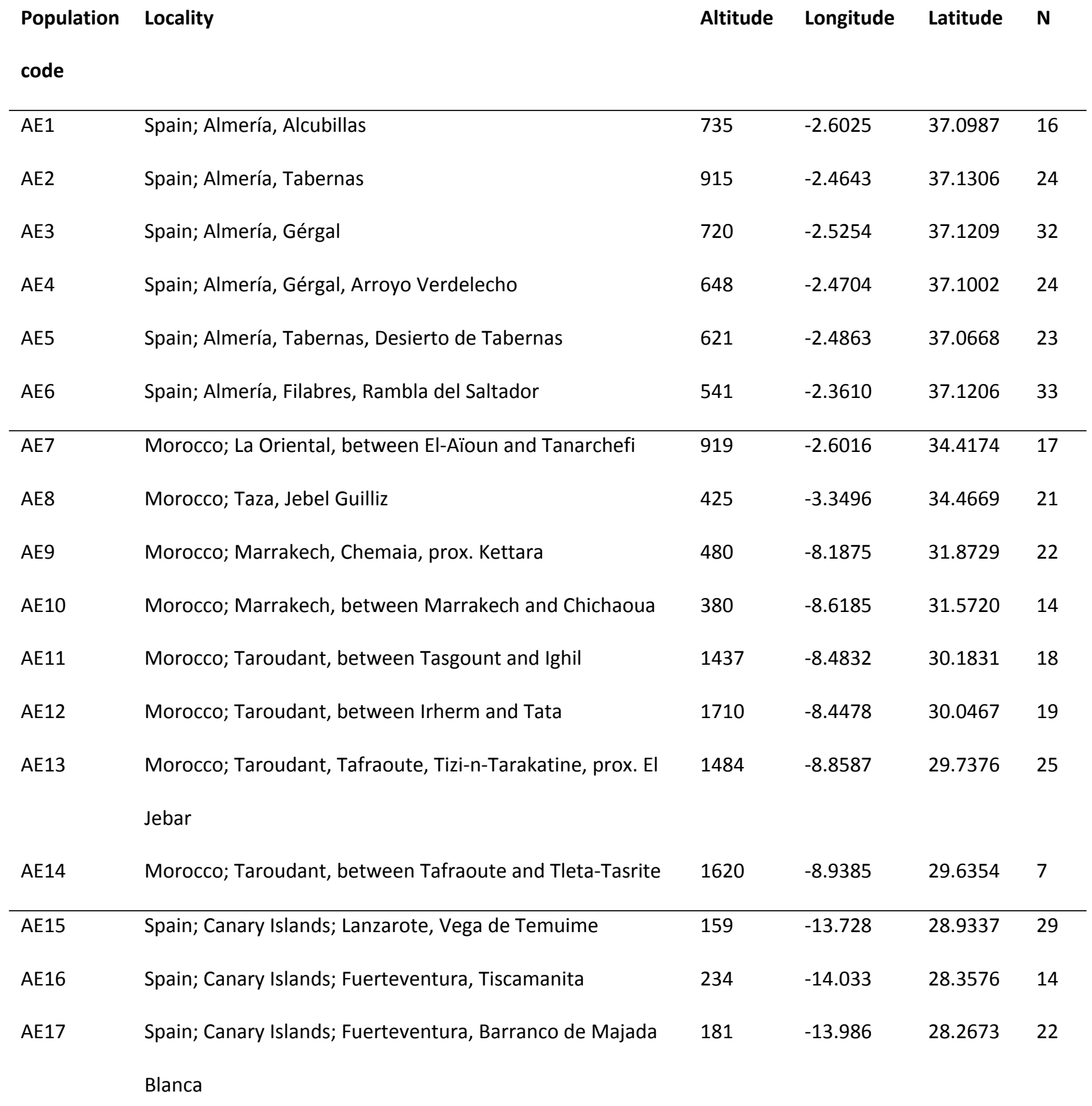


Table 2. PCR primers and conditions used to obtain cpDNA sequence data for Astragalus edulis.

\begin{tabular}{|c|c|c|c|c|c|c|}
\hline $\begin{array}{l}\text { cpDNA } \\
\text { region }\end{array}$ & $\begin{array}{l}\text { Forward } \\
\text { primer }\end{array}$ & $\begin{array}{l}\text { Reverse } \\
\text { primer }\end{array}$ & $\begin{array}{c}\text { Denaturation } \\
\text { Temperature/Time }\end{array}$ & $\begin{array}{c}\text { Annealing } \\
\text { Temperature/Time }\end{array}$ & $\begin{array}{c}\text { Extension } \\
\text { Temperature/Time }\end{array}$ & Cycles \\
\hline trnG-trnS & $3^{\prime} \operatorname{trn} G^{U U C}$ & $\operatorname{trn} S^{\mathrm{GCU}}$ & $95 ㄷ / 30^{\prime \prime}$ & $62^{\circ} \mathrm{C} / 30^{\prime \prime}$ & $72 \circ / 1^{\prime} 30^{\prime \prime}$ & 35 \\
\hline $\operatorname{trnC}$-rpoB & $\operatorname{trn} C^{G C A} R$ & rpoB & $95 ㄷ / 30^{\prime \prime}$ & $55^{\circ} \mathrm{C} / 30^{\prime \prime}$ & $72 \circ / 1^{\prime} 30^{\prime \prime}$ & 35 \\
\hline $\operatorname{tabC}-\operatorname{tab} \mathrm{F}$ & $\operatorname{trn} L^{U A A} 5^{\prime}$ & $\operatorname{trn} F^{G A A}$ & $95 \div C / 30^{\prime \prime}$ & $52^{\circ} \mathrm{C} / 30^{\prime \prime}$ & $72 \circ / 2^{\prime} 30^{\prime \prime}$ & 35 \\
\hline
\end{tabular}


600 Table 3. Population, geographical groups, AFLP derived diversity and rarity descriptors, rarity assessment

601 through qualitative variables (see text) and cpDNA haplotypes (endemic ones in bold characters) for the 602 studied population of $A$. edulis. Geographical groups: $\mathrm{IP}=\mathrm{Iberian}$ Peninsula, $\mathrm{M}=\mathrm{Morocco}, \mathrm{Cl}=\mathrm{Canary}$

603 Islands. $h_{\text {Nei }}=$ Nei's diversity index (Nei 1987). DW= frequency down-weighted marker values. $\mathrm{N}_{\mathrm{r}}=$ 604 number of rare alleles. $\mathrm{H}=$ haplotype.

\begin{tabular}{|c|c|c|c|c|c|c|c|c|c|}
\hline Population & $\begin{array}{l}\text { Geographica } \\
\text { I group }\end{array}$ & $h_{\text {Nei }}$ & DW & $N_{r}$ & $\begin{array}{l}\text { Occupation } \\
\text { area }\end{array}$ & $\begin{array}{l}\text { Population } \\
\text { size }\end{array}$ & Vulnerability & Legal status & H \\
\hline$\overline{\mathrm{AE} 1}$ & IP & 0.101 & 3.505 & 31 & small & reduced & critical & unprotected & IV,V \\
\hline AE2 & IP & 0.103 & 2.226 & 25 & large & high & moderate & protected & $\mathrm{I}, \mathrm{V}$ \\
\hline AE3 & IP & 0.125 & 3.298 & 45 & large & high & moderate & protected & $\mathrm{I}, \mathrm{IV}$ \\
\hline AE4 & IP & 0.151 & 4.038 & 38 & large & high & acceptable & protected & I,III \\
\hline AE5 & IP & 0.155 & 4.644 & 47 & large & high & acceptable & protected & IV,V \\
\hline AE6 & IP & 0.076 & 1.507 & 16 & large & reduced & moderate & unprotected & I \\
\hline AE7 & $M$ & 0.066 & 1.754 & 14 & small & reduced & critical & unprotected & I \\
\hline AE8 & $M$ & 0.119 & 3.2 & 33 & large & high & moderate & unprotected & I \\
\hline AE9 & M & 0.114 & 3.218 & 51 & small & reduced & critical & unprotected & IV \\
\hline AE10 & $M$ & 0.082 & 1.728 & 8 & small & reduced & moderate & unprotected & VI \\
\hline AE11 & $M$ & 0.104 & 2.924 & 27 & large & reduced & moderate & unprotected & II \\
\hline AE12 & $M$ & 0.097 & 2.834 & 30 & small & reduced & critical & unprotected & IV \\
\hline AE13 & M & 0.103 & 2.815 & 33 & large & high & moderate & unprotected & IV \\
\hline AE14 & M & 0.076 & 2.08 & 12 & small & reduced & critical & unprotected & IV \\
\hline AE15 & $\mathrm{Cl}$ & 0.074 & 2.862 & 14 & small & high & moderate & unprotected & VII \\
\hline AE16 & $\mathrm{Cl}$ & 0.127 & 5.713 & 37 & small & reduced & moderate & unprotected & VII \\
\hline AE17 & $\mathrm{Cl}$ & 0.110 & 4.996 & 55 & large & reduced & acceptable & unprotected & VII \\
\hline
\end{tabular}


607 Table 4. Comparison of analyses of molecular variance (AMOVA), based on AFLP data, of Astragalus

608 edulis across the main geographical groups ( $\mathrm{IP}=\mathrm{Iberian}$ Peninsula, $\mathrm{M}=\mathrm{Morocco}, \mathrm{Cl}=\mathrm{Canary}$ Islands), and 609 populations (are shown in brackets) (see Table 1 and Figure 1).

\begin{tabular}{|c|c|c|c|c|c|c|}
\hline Source of variation & MS & d.f. & $\begin{array}{l}\text { Absolute } \\
\text { variation }\end{array}$ & $\begin{array}{l}\text { Percentage } \\
\text { of variation }\end{array}$ & $\mathbf{F}_{\mathrm{ST}}$ & $\begin{array}{l}\text { 95\% confidence } \\
\text { interval }\end{array}$ \\
\hline One group [A1-A17] & & & & & 0.289 & $26.2-30.8$ \\
\hline Among populations & 9268.217 & 16 & 24.641 & 28.94 & & \\
\hline Within populations & 20755.722 & 343 & 60.512 & 71.06 & & \\
\hline \multicolumn{5}{|c|}{ Three groups: IP(A1-A6); M(A7-A14) and C(A15-A17) } & 0.346 & $21.1-26.8$ \\
\hline Among groups & 5694.211 & 2 & 22.611 & 24.44 & & \\
\hline Among populations & 3574.006 & 14 & 9.383 & 10.14 & & \\
\hline Within populations & 20755.722 & 343 & 60.512 & 65.41 & & \\
\hline
\end{tabular}


612 Table 5. Associations between geographical and qualitative population variables (factors) and genetic

613 diversity and rarity $\left(\mathrm{h}_{\mathrm{Nei}}=\right.$ Nei's diversity index, Nei 1987. DW= frequency down-weighted marker values.

$614 \mathrm{~N}_{\mathrm{r}}=$ number of rare alleles), as tested using the generalized linear model (GLM). Geographical groups:

$615 \mathrm{IP}=\mathrm{Iberian}$ Peninsula, $\mathrm{M}=\mathrm{Morocco}, \mathrm{Cl}=$ Canary Islands. All the values are indicated as mean $\pm \mathrm{SE}$. Different

616 letters indicate significant differences in the multiple comparison test at $\mathrm{P}<0.05$, performed after the 617 bootstrapped GLM.

\begin{tabular}{lllll} 
Factor & Level & $\mathbf{h}_{\mathrm{Nei}}$ & $\mathrm{DW}$ & $\mathbf{N}_{\mathbf{r}}$ \\
\hline Geographical group & $\mathrm{IP}$ & $0.12 \pm 0.01 \mathrm{a}$ & $3.20 \pm 0.47 \mathrm{ab}$ & $33.66 \pm 4.89 \mathrm{a}$ \\
& $\mathrm{M}$ & $0.10 \pm 0.01 \mathrm{a}$ & $2.57 \pm 0.22 \mathrm{~b}$ & $26.00 \pm 5.00 \mathrm{~b}$ \\
& $\mathrm{Cl}$ & $0.10 \pm 0.03 \mathrm{a}$ & $4.52 \pm 0.86 \mathrm{a}$ & $35.33 \pm 11.86 \mathrm{a}$ \\
\hline Occupation area & large & $0.12 \pm 0.01 \mathrm{a}$ & $3.30 \pm 0.37 \mathrm{a}$ & $35.44 \pm 4.06 \mathrm{a}$ \\
& small & $0.09 \pm 0.01 \mathrm{~b}$ & $2.96 \pm 0.46 \mathrm{a}$ & $24.62 \pm 5.31 \mathrm{~b}$ \\
\hline Population size & large & $0.12 \pm 0.01 \mathrm{a}$ & $3.29 \pm 0.31 \mathrm{a}$ & $33.57 \pm 4.33 \mathrm{a}$ \\
& small & $0.09 \pm 0.01 \mathrm{~b}$ & $3.03 \pm 0.45 \mathrm{a}$ & $28.10 \pm 5.11 \mathrm{~b}$ \\
\hline Vulnerability & stable & & & \\
\hline & declining & $0.14 \pm 0.01 \mathrm{a}$ & $4.56 \pm 0.28 \mathrm{a}$ & $46.66 \pm 4.91 \mathrm{a}$ \\
& critically declining & $0.09 \pm 0.01 \mathrm{~b}$ & $2.68 \pm 0.33 \mathrm{~b}$ & $27.60 \pm 7.05 \mathrm{~b}$ \\
\hline Legal status & protected & $0.13 \pm 0.02 \mathrm{a}$ & $3.55 \pm 0.52 \mathrm{a}$ & $38.75 \pm 4.97 \mathrm{a}$ \\
& unprotected & $0.09 \pm 0.02 \mathrm{~b}$ & $3.01 \pm 0.34 \mathrm{a}$ & $27.77 \pm 4.01 \mathrm{~b}$
\end{tabular}

618

619 
620 Figure 1. Location of the populations of Astragalus edulis sampled for this study.

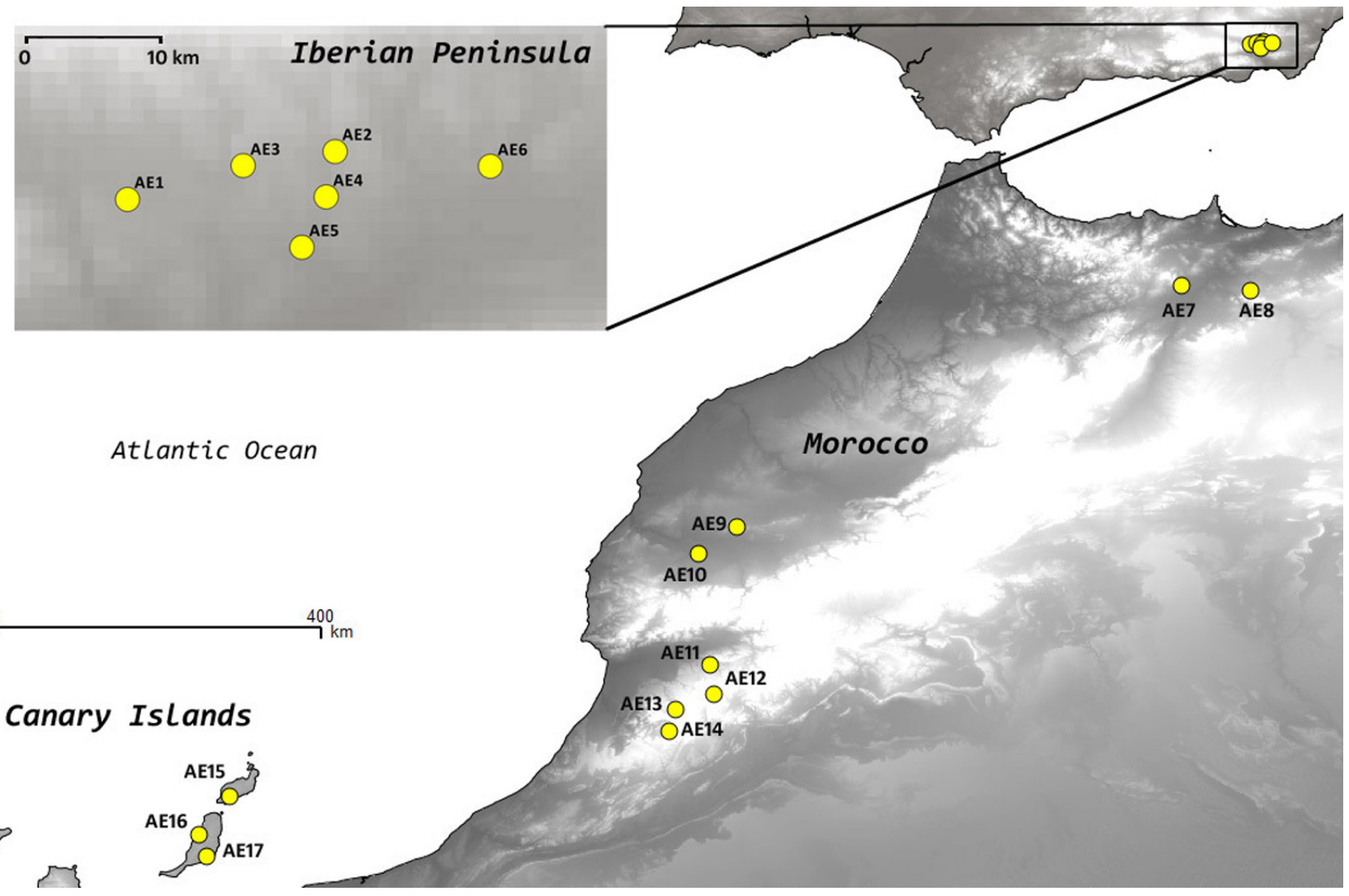

622 
623 Figure 2. Cluster analysis of genetic diversity, using AFLPs, in Astragalus edulis. a. Neighbour-Joining 624 analysis, BS values are indicated; $\mathrm{b}$. $\mathrm{PCoA}$. Geographical groups: $\mathrm{IP}=\mathrm{Iberian}$ Peninsula, $\mathrm{M}=\mathrm{Morocco}, \mathrm{Cl}=$ 625 Canary Islands.
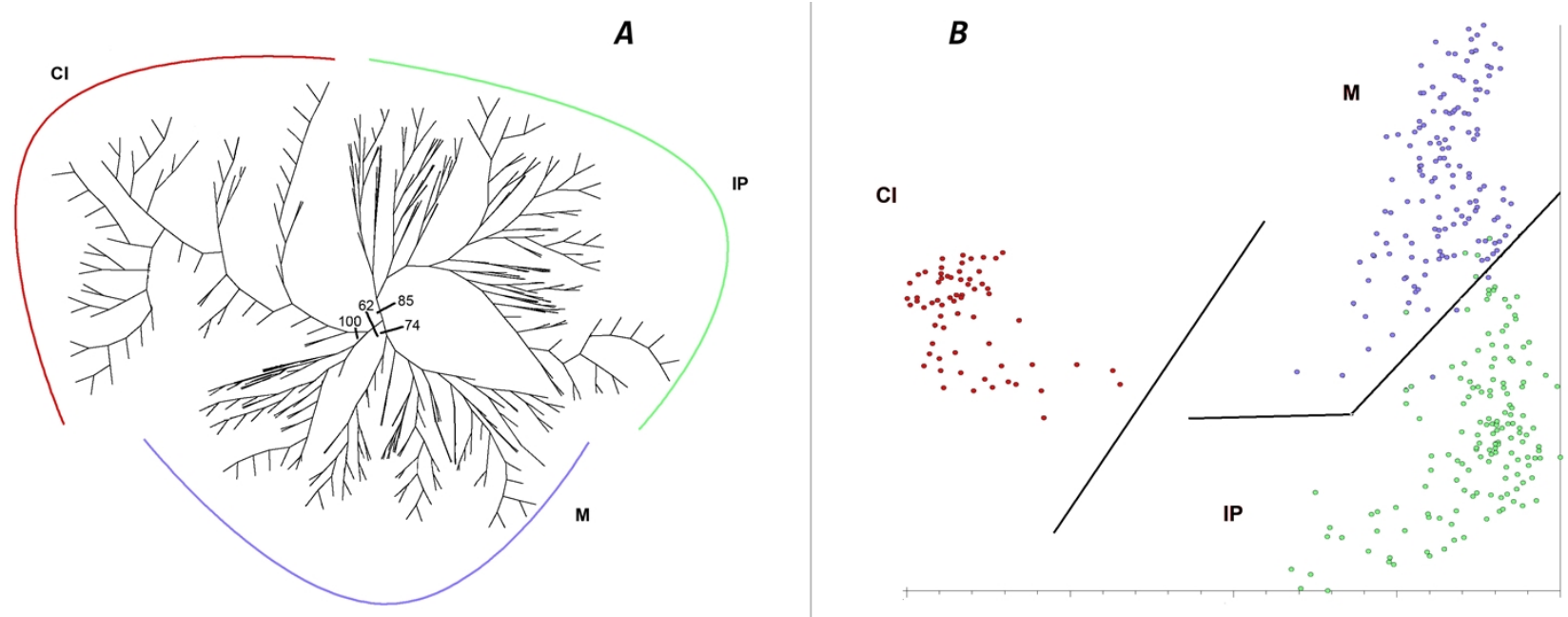

626

627 
628 Figure 3. Statistical parsimony network and geographical distribution of plastid DNA haplotypes. The

629 insert shows populations within the Iberian Peninsula. The small white circle represents a missing

630 intermediate haplotype. Sectors within circles in the map indicate the presence of different haplotypes

631 in different individuals of the same population.

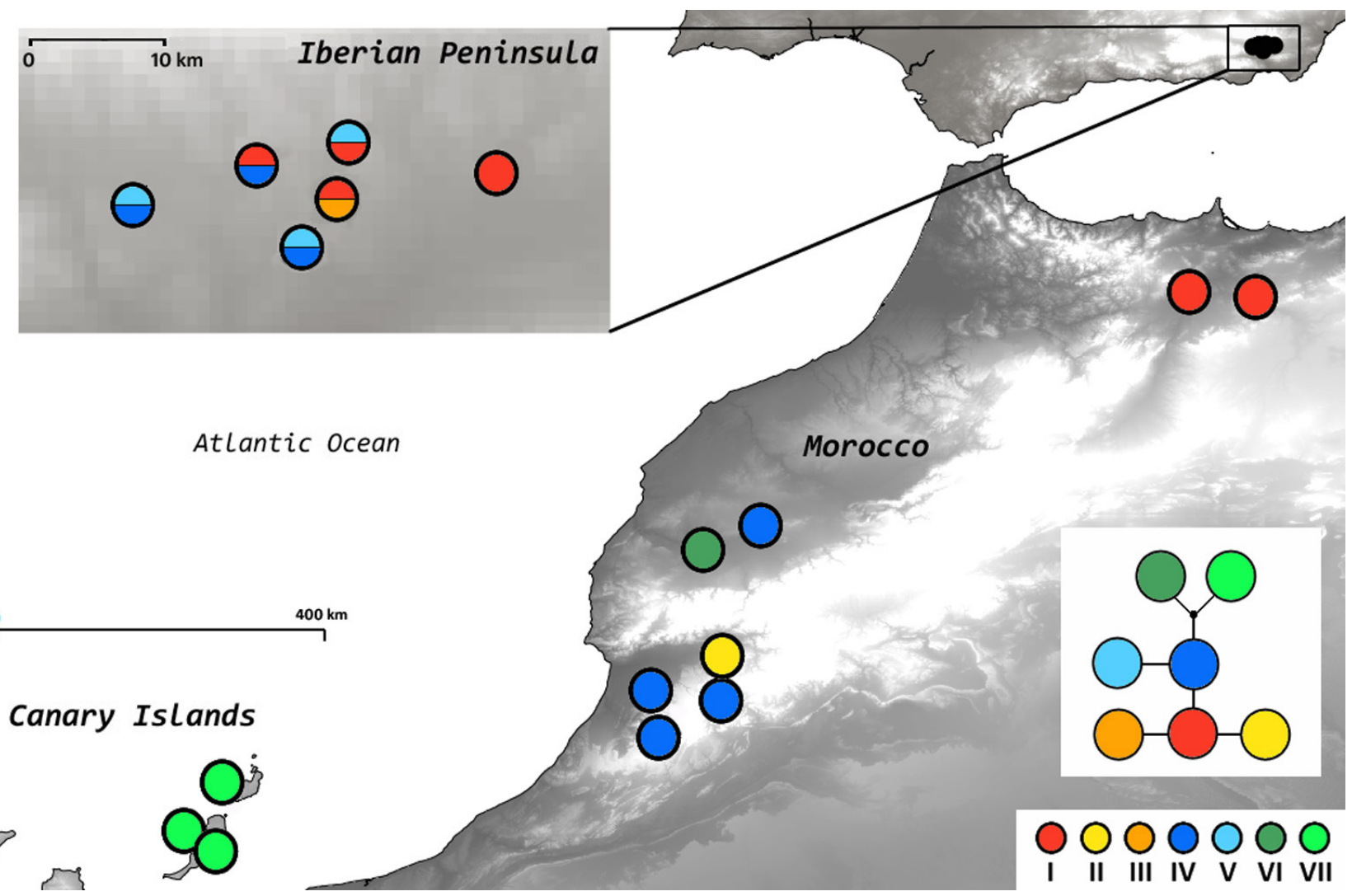

633 